Prospect. Univ. (2010)

\title{
EXTRACCIÓN DE ACEITE ESENCIAL DE CEDRÓN (Aloysia Triphylla L'Herit) POR ARRASTRE DE VAPOR EN EL DISTRITO DE TARMA 32
}

Cuadrado Campo, Walter ${ }^{1}$, Carhuallanqui Ávila, Shalin²

Facultad de Ciencias Aplicadas de la Universidad Nacional del Centro del Perú

\begin{abstract}
RESUMEN
El trabajo de investigación titulado Extracción de Aceite Esencial de Cedrón (Aloysia Triphylla L'Herit) por Arrastre de Vapor en el distrito de Tarma, tiene como objetivo determinar las características fisicoquímicas y sensoriales del aceite esencial de cedrón. Se utilizó toda la planta en estado vegetativo antes de floración en dos condiciones de secado al medio ambiente y secado a $40^{\circ} \mathrm{C}$. Las operaciones de obtención de aceite esencial fueron: Recolección, transporte, selección, deshidratado, acondicionamiento, extracción, descarga. La caracterización físico química del aceite esencial de cedrón secada al medio ambiente fue el siguiente: Aspecto líquido oleoso, color transparente ligeramente amarillo, olor fuerte agradable, sabor picante, densidad relativa 0,888, gravedad específica 0.8991, inmiscible en agua, ligeramente miscible en alcohol al $70 \%$, miscible en éter, cloroformo y tetracloruro de carbono, acidez de 0,040 y pH 2.12. El secado a $40^{\circ} \mathrm{C}$ : Aspecto líquido oleoso, color transparente ligeramente amarillo, olor fuerte agradable, sabor picante, densidad relativa 0,875 , gravedad especifica 0.8980 , inmiscible en agua, ligeramente miscible en alcohol al 70\%, miscible en éter, cloroformo y una acidez de 0,053 y pH 2.1, el índice de saponificación es igual para ambos casos 0,40 . Finalmente el rendimiento obtenido de la extracción de aceite esencial fue de $0,247 \%$ de tejido seco al medio ambiente y $0,243 \%$ tejido seco a $40^{\circ} \mathrm{C}$ en promedio. Este trabajo de investigación busca contribuir al desarrollo de la actividad agroindustrial de la zona, dando alternativas de industrialización de las materias primas que se producen en nuestra zona, como esta hierba aromática.
\end{abstract}

Palabras clave: cedrón, aceite esencial, arrastre de vapor, índice de refracción.

\section{ESSENTIAL OIL EXTRACTION CEDRON (Aloysia triphylla L'Herit) BY STEAM IN THE DISTRICT OF TARMA}

\begin{abstract}
The paper titled Removing Cedrón Essential Oil (Aloysia triphylla L'Herit) by steam in the district of Tarma, aims to determine the physicochemical and sensory characteristics of the essential oil of lemon verbena. Whole plant was used in a vegetative state before flowering in two drying conditions and drying environment at $40^{\circ} \mathrm{C}$. The operations for obtaining the essential oil were: Collection, transport, sorting, dehydrated, packaging, mining, download. The physical and chemical characterization of dried lemon verbena essential oil to the environment was as follows: Appearance oily liquid, slightly yellow transparent color, strong odor pleasant, spicy flavor, relative density 0.888 , specific gravity 0.8991 , insoluble in water, slightly miscible in alcohol $70 \%$, miscible in ether, chloroform and carbon tetrachloride, acidity of 0.040 and $\mathrm{pH} 2.12$ and dried at $40^{\circ} \mathrm{C}$ : Appearance oily liquid, transparent color light yellow, strong odor pleasant, spicy flavor, relative density 0.875 , specific gravity 0.8980 , insoluble in water, slightly miscible in alcohol $70 \%$, miscible in ether, chloroform and an acidity of 0.053 and pH 2.1, saponification is the same for both cases 0.40 . Finally the yield of extraction of essential oil were $0.247 \%$ of dry tissue environment and $0.243 \%$ dry tissue at $40^{\circ} \mathrm{C}$ on average. This research seeks to contribute to the development of agro-industrial activity in the area, giving alternatives industrialization of raw materials that occur in our area, as this herb.
\end{abstract}

Key words: cedrón, essential oil, Steam-driven dragging, refraction index.

32 Trabajo de investigación fue recibido el 07/05/2010 retornado para su revisión el 15/06/2010 y aprobado para su publicación 16/11/2010. 


\section{INTRODUCCIÓN}

Tarma cuenta con potencial en biodiversidad ecológica, como son las plantas aromáticas nativas silvestres, que han sido utilizadas en la medicina andina. Estas plantas aromáticas contienen aceites esenciales, que son sustancias odoríferas de naturaleza oleosa, son muy numerosos y están ampliamente distribuidos en distintas partes del vegetal: en las raíces, tallos, hojas, flores y frutos. Estos aceites esenciales son componentes heterogéneos de terpenos, sesquiterpenos, ácidos, ésteres, fenoles, lactonas, etc (Martinez M. A, 2003). El método de destilación por arrastre con vapor separa sustancias orgánicas insolubles en agua y ligeramente volátiles de otros productos no volátiles que se encuentran en la mezcla (resinas o sales inorgánicas), las sustancias arrastrables con vapor son inmiscibles en agua, tienen presión de vapor baja y punto de ebullición alto, los vapores saturados de los líquidos inmiscibles siguen la ley de Dalton sobre las presiones parciales. Este método busca obtener un alto rendimiento de aceite esencial del cedrón con características físico químicas adecuadas para la utilización en la agroindustria.

Por lo que se realizó la investigación titulada Extracción de Aceite Esencial de Cedrón por Arrastre de Vapor (Aloysia Triphylla L'Herit) en el distrito de Tarma. Las operaciones de extracción fueron: Selección de cedrón, limpieza, eliminando desechos, selección de temperaturas de secado a temperatura ambiente $18^{\circ} \mathrm{C}$ y a $40^{\circ} \mathrm{C}$ secado en estufa, extracción de aceite de cedrón por arrastre de vapor y la caracterización química y fisicoquímica del aceite. El uso de los aceites esenciales de condimentos y especias tanto en la industria de alimentos como en la industria farmacéutica es cada vez más generalizado, debido en parte a la homogeneidad del aroma y a la minimización de las posibilidades de contaminación microbiana, cuando se compara con el uso directo de tales especias y condimentos.

Este trabajo de investigación comprobó la hipótesis que con el método de extracción de aceite por arrastre de vapor se obtuvo un alto rendimiento de aceite esencial de cedrón, influyendo en las características físico-químicas el aceite esencial, siendo adecuadas para la utilización en la agroindustria.

El objetivo de este trabajo de investigación fue determinar las características fisicoquímicas del aceite esencial del cedrón secado a diferentes secados por el método de arrastre de vapor.

Dentro de los objetivos específicos que busca esta investigación se encuentran a) Determinar las características químicas del cedrón, b) Obtener el flujo grama del proceso de extracción de aceite esencial de cedrón por el método de arrastre de vapor, c) Determinar el rendimiento de aceite esencial de cedrón a diferentes secados y d) Determinar las características fisicoquímicas y sensoriales del aceite esencial de cedrón a diferentes secados.

\section{MATERIALES Y MÉTODOS}

\section{Lugar de ejecución:}

Los ensayos experimentales se realizaron en las instalaciones de la Facultad de Ciencias Aplicadas y laboratorios de la FAllA de la UNCP Durante el periodo del 2008.

\section{Materia prima:}

Se utilizó el cedrón $10 \mathrm{Kg}$ de los alrededores de la provincia de Tarma.

\section{Equipos, materiales y reactivos}

Materiales y equipos: Auto clave de acero inoxidable, potenciómetro, refrigerante de espiras de acero inoxidable, refractómetro $\mathrm{ABBE}$ con termómetro, estufa, balanza de precisión, picnómetro, vasos de precipitación, frascos de color ámbar, pera de decantación.

Reactivos: Sulfato de magnesio anhidro, hidróxido de potasio, ácido clorhídrico, solución de ácido acéticocloroformo, Solución saturada de yoduro de potasio, tiosulfato de sodio.

\section{Metodología Experimental}

\section{Métodos de análisis}

\section{Características físicas del Cedrón}

Se realizó la evolución física del cedrón, recomendado por Carhuancho F., 2000.

\section{Caracterización fisicoquímica de aceite esencial} Índice de refracción. Método recomendado por la NTP 319.075 (1987), Densidad: Método recomendado por la NTP 319.081 (1987), Índice de acidez: Método recomendado por la NTP 319.085 (1987), Características Físico Sensorial: Método tomado de Zarate (19), pH: Método recomendado por la WTW (2000). 
Metodología de la descripción de la obtención de aceite esencial de cedrón

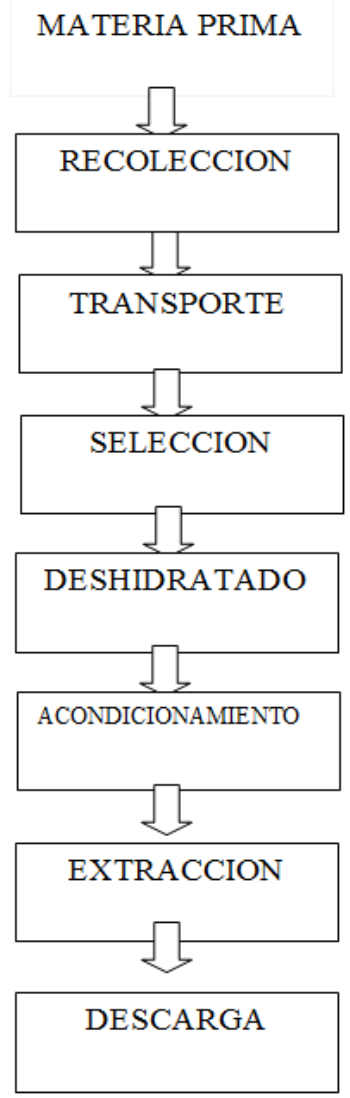

Especie vegetal: Aloysia triphylla L'Herit Estado:

Planta silvestre nativa Recolección: Manual Estado vegetativo: Antes de floración Empaque: Costales con mallas para la aireación Temperatura: Ambiental Inspección visual: Partículas extrañas Pardeamiento Insectos Ventilación: No asistida Temperatura: Medio Ambiente y a $40^{\circ} \mathrm{C}$

Humedad material: Tejido deshidratado Carga material vegetal: $720 \mathrm{~g}$.

Tiempo:

2 horas

Fluido de arrastre:

Vapor de agua

Temperatura de

autoclave

Descarga:

Aceite esencial

Material vegetal

Temperatura: Menor a la temperatura de extracción

Fuente: García (2000)

Figura 2: Flujograma general de la obtención de aceite esencial de cedrón

\section{DISEÑO EXPERIMENTAL:}

Esta Investigación realizada es de nivel experimental. Con los datos experimentales obtenidos de la caracterización del aceite esencial de cedrón se procedió a realizar un DCA y su respectivo Análisis de varianza de los valores de la caracterización del aceite esencial.

Variables Independientes: Tiempo de secado (18 y $\left.40^{\circ} \mathrm{C}\right)$

Variables Dependientes: Características químicas y fisicoquímicas del aceite
Figura 1: Diseño experimental propuesto

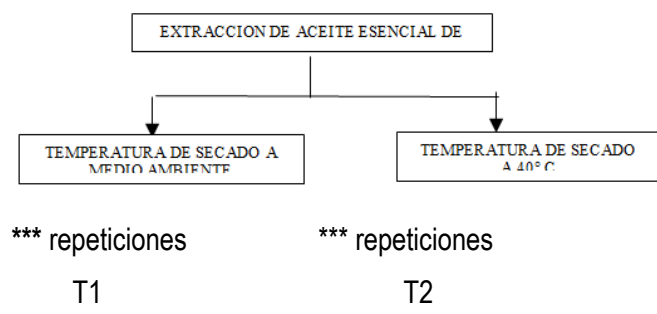

RESULTADOS

EVALUACIÓN DEL CEDRÓN

\section{Características del Cedrón}

En el cuadro 1, se muestra los resultados de las características del Cedrón:

CUADRO 1: Características del cedrón

\begin{tabular}{cc}
\hline Características & \\
\hline - Altura & 1.70 m aprox. \\
- Color & Verde pálido \\
- Olor & Característico \\
\hline
\end{tabular}

\section{CARACTERIZACIÓN DEL ACEITE ESENCIAL DE CEDRÓN}

Diagrama de producción definitivo de la obtención de aceite esencial

El diagrama de flujo definitivo, para la obtención de aceite esencial de Cedrón, obtenidas a dos temperaturas de secado de la materia prima, se muestra en la figura 2.

Balance de materia y determinación del rendimiento

El balance de materia y determinación del rendimiento del aceite esencial de cedrón, se observa en la Figura 3 y 4.

Figura 3: $\quad$ Balance de materia y determinación del rendimiento del aceite esencial de cedrón secado a medio ambiente 


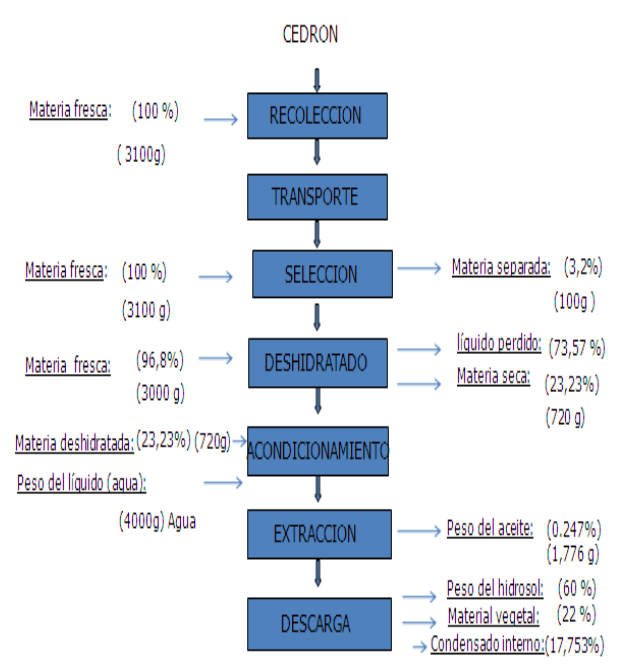

Figura 4: Balance de materia y determinación del rendimiento del aceite esencial de cedrón secado a $40{ }^{\circ} \mathrm{C}$

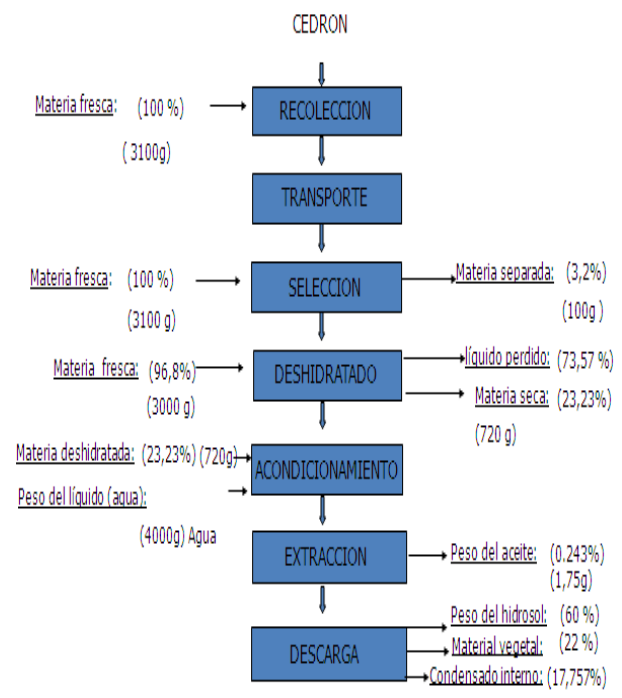

Evaluación físico químico del Aceite esencial

GRÁFICO 1: DATOS DEL ANÁLISIS FÍSICO

QUÍMICO DEL ACEITE ESENCIAL
Analisis de densidad, indice de refracción, gravedad especifica

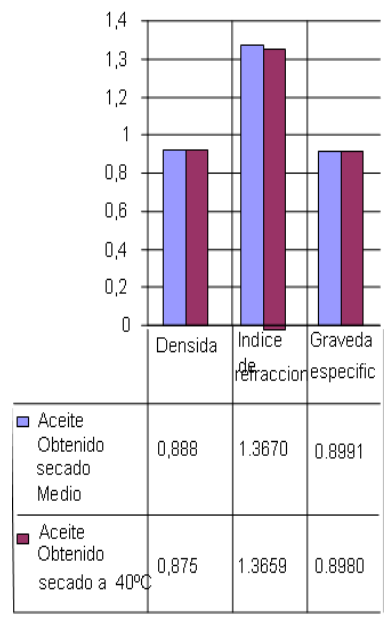

$\square$ Aceite esencial Cedron: Secado a medio ambiente

- Aceite

Cedron: Secado a $40^{\circ} \mathrm{C}$

La evaluación físico química del aceite esencial de cedrón, se presenta el cuadro 2 y grafico 1.

Cuadro 2.- Evaluación fisicoquímica del aceite esencial de cedrón, secado a medio ambiente y a $40^{\circ} \mathrm{C}$

\begin{tabular}{|c|c|c|}
\hline \multirow[t]{2}{*}{ Componentes } & \multicolumn{2}{|c|}{ Aceite esencial obtenido: } \\
\hline & $\begin{array}{c}\text { Cedrón secado a medio } \\
\text { ambiente }\end{array}$ & Cedrón secado a $40^{\circ} \mathrm{C}$ \\
\hline Densidad & 0,888 & 0,875 \\
\hline Índice de & 1,3670 & 1,3659 \\
\hline refracción $\left(20^{\circ} \mathrm{C}\right)$ & 0,8991 & 0,8980 \\
\hline Gravedad & 0,041 & 0,053 \\
\hline especifica $\left(25^{\circ} \mathrm{C}\right)$ & 2,12 & 2,11 \\
\hline Índice de acidez & 0,40 & 0,40 \\
\hline $\begin{array}{l}\mathrm{pH} \\
\text { Îndice de } \\
\text { saponificación }\end{array}$ & $\begin{array}{l}\text { Inmiscible en agua, } \\
\text { ligeramente miscible en } \\
\text { alcohol a } 70 \% \text {, miscible } \\
\text { en éter, cloroformo y } \\
\text { tetracloruro de carbono. }\end{array}$ & $\begin{array}{l}\text { Inmiscible en agua, } \\
\text { ligeramente miscible en } \\
\text { alcohol a } 70 \% \text {, miscible } \\
\text { en éter, cloroformo y } \\
\text { tetracloruro de carbono. }\end{array}$ \\
\hline Miscibilidad & $\begin{array}{lr}\text { Liquido } & \text { oleoso, } \\
\text { transparente } & \text { color }\end{array}$ & $\begin{array}{lr}\text { Liquido } & \text { oleoso, } \\
\text { transparente } & \text { color }\end{array}$ \\
\hline & ligeramente amarillo, olor & ligeramente amarillo, olor \\
\hline & $\begin{array}{l}\text { fuerte y sabor } \\
\text { característico }\end{array}$ & $\begin{array}{l}\text { fuerte y sabor } \\
\text { característico. }\end{array}$ \\
\hline Aspecto & & \\
\hline
\end{tabular}

\section{DISCUSIÓN}

\section{EVALUACIÓN DEL CEDRÓN}

\section{Características del Cedrón}

El Cedrón es una planta arbustiva que mide $1.70 \mathrm{~m}$ aproximadamente y está dentro de lo que reporta Zarate (1989) que puede medir entre 1,50 y 2,50 metros de altura, sus tallos son largos, leñosos, redondos 0 angulosos, ramificados en la parte superior, provistos de finas rayas lineares. Las hojas son simples, rugosas, de color verde pálido, de un agradable olor a limón. 


\section{CARACTERIZACIÓN DEL ACEITE ESENCIAL DE CEDRÓN}

\section{Diagrama de producción definitivo de la obtención}

\section{de aceite esencial}

El procedimiento de extracción de aceite esencial, se realizó en base al flujograma propuesto (6), para la extracción de aceite esencial, es la destilación por arrastre de vapor de agua, es una operación que permite destilar sustancias orgánicas inmiscibles 0 poco miscibles con el agua a temperatura menores a los puntos de ebullición de ambos. La operación de extracción es un punto crítico ya que en esta operación el vapor de agua atraviesa la hierba colocada en el recipiente, extrae y arrastra el aceite esencial que tiene bajo punto de volatilización y lo lleva hasta el refrigerante, donde al enfriarse se condensa y se separa el agua del aceite por densidad. $\mathrm{Si}$ el aceite es menos denso queda en la superficie y si es más denso que el agua, va al fondo. De esta manera es fácil separarlo.

\section{Balance de materia y determinación del rendimiento}

Realizándose la determinación de rendimientos de extracción e identificado el tratamiento óptimo, el mejor resultado obtenido fue de la materia prima secada al medio ambiente por que la temperatura no superaba los $17-18^{\circ} \mathrm{C}$ y existe una menor pérdida de los compuestos volátiles, el tiempo de secado estuvo comprendido entre 5 días y la humedad final de la materia prima varía entre $13 \%$ con un rendimiento en peso seco de $35 \%$ el porcentaje de aceite obtenido de la muestra secado al medio ambiente fue de $0,247 \%$ y de aceite obtenido de la muestra secado a $40^{\circ} \mathrm{C}$ fue de $0,243 \%$, que está dentro del rango que las hojas oreadas rinden entre el $0,1 \mathrm{y}$ el $1,5 \%$. Cabe resaltar que el proceso de deshidratado del material vegetal recolectado, aparte de eliminar agua, permite obtener relativamente un mayor rendimiento de obtención de aceite esencial, debido a que en estas condiciones, la superficie de contacto que se produce por este proceso le es favorable por que ayuda a incrementar la superficie de contacto con el vehículo de extracción.

\section{Evaluación físico química del aceite esencial}

Al obtener el aceite esencial óptimo en base al máximo rendimiento se realizaron los siguientes análisis fisicoquímicos al aceite esencial óptimo de cedrón. La caracterización de los aceites esenciales por su naturaleza química consiste en la evaluación de su densidad, índice de refracción y sus características sensoriales (olor, color, consistencia y apariencia general). Estas características están ligadas a la naturaleza misma de los lípidos que son propios del cedrón.

Los resultados de la evaluación físico química, se presentan en el Cuadro 2 y, en el Gráfico 1 se muestran los resultados promedios (tres repeticiones) de la evaluación del aceite de cedrón, donde se observa que la densidad del aceite obtenido del Cedrón secado al medio ambiente es ligeramente superior al del aceite obtenido del secado del Cedrón a $40^{\circ} \mathrm{C}$. Como todo aceite es inmiscible en agua, pero ligeramente miscible en alcohol a $70 \%$, miscible en éter, cloroformo y tetracloruro de carbono, presenta un aspecto de líquido oleoso, transparente color ligeramente amarillo, olor fuerte pero agradable, sabor picante.

Los resultados de la evaluación del aceite esencial de cedrón, donde se observa que la acidez del aceite obtenido de la planta del secado al medio ambiente es de 0,041 y el del aceite obtenido de la planta secada a $40^{\circ} \mathrm{C}$ es de 0,053 ; presentan unos $\mathrm{pH}$ de 2,12 y 2,11 respectivamente, la acidez (miligramos de hidróxido de potasio requeridos para neutralizar los ácidos grasos libres en un gramo de muestra) baja significa que el aceite procede de materia prima sana y ha sido elaborado en condiciones óptimas. La acidez puede ser resultado de una oxidación o contaminación y en este caso los ácidos grasos que ocasionan la acidez pueden tener diferentes pesos moleculares de aquellos presentes en forma esterificada en los triglicéridos presentes en el aceite.

El índice de saponificación es igual para ambos casos 0,40 . Esto nos da una indicación del peso molecular de dichos ácidos y el índice de refracción del aceite obtenido de la planta del secado al medio ambiente es de 1,3670 y el del aceite obtenido de la planta secada a $40^{\circ} \mathrm{C}$ es de 1,3659 . Este índice de refracción es un valor que relaciona el ángulo de incidencia de un rayo luminoso sobre la muestra con el ángulo de refracción, este valor está ligado a la instauración de los ácidos grasos, el aumento de índice de refracción en el aceite esencial obtenida por planta secada a $40^{\circ} \mathrm{C}$ se debe al aumento del grado de instauración y el porcentaje de ácidos insaturados y por el incremento del peso molecular, influenciado por el deterioro oxidativo que ha sufrido la planta. 
Si bien la composición química de los aceites es muy variada, todos ellos poseen varias propiedades físicas en común, por ejemplo: tienen alto índice de refracción, son ópticamente activos. Estas cualidades tecnofuncionales, están determinados por sus propiedades físicas y químicas, por lo que se evaluó dichos parámetros bajo un protocolo establecido. Estos valores han sido afectados por las condiciones ecológicas en que se desarrollan los organismos de donde provienen los lípidos, interviniendo la naturaleza de los suelos, la alimentación, la altitud, la altura.

Estos índices determinados, contribuyen a la identificación y estando dentro de los límites permiten determinar el grado de pureza de las grasas y aceites.

Los aceites esenciales consisten en mezclas de productos químicos que a menudo son muy complejas. En su mayoría están constituidos por terpenos, que son hidrocarburos cuya fórmula es $\mathrm{C} 12$ H16. Los terpenos más comunes son el limoneno y el pineno. Estos terpenos se oxidan naturalmente, por lo que muchas veces es necesario separarlos, obteniendo un producto de mayor valor que se conoce como aceite esencial deterpenada. Su composición exacta se puede obtener mediante una cromatografía gaseosa. Es importante conocer ésta a los efectos de poder fijar precio al producto, ya que ésta varía según su composición química. Los mayores consumidores de aceites deterpenados son las industrias de perfumería y cosmeatría (9).

\section{CONCLUSIONES}

- Las operaciones de obtención de aceite esencial fueron: Recolección, transporte, selección, deshidratado, acondicionamiento y extracción.

- El rendimiento promedio de extracción de aceite esencial de cedrón es de $0,247 \%$ en tejido secado al medio ambiente y $0,243 \%$ en tejido deshidratado a $40^{\circ} \mathrm{C}$ del material vegetal en estado vegetativo antes de la floración.

- El aceite esencial de cedrón obtenido por secado a $40^{\circ} \mathrm{C}$ muestra las siguientes características físico químicas: Densidad 0,875; Índice de refracción $\left(20^{\circ} \mathrm{C}\right)$ 1,3659; gravedad especifica $\left(25^{\circ} \mathrm{C}\right)$ 0,8980; acidez de 0,053\%. El aceite obtenido por la planta secada a medio ambiente presento una densidad de 0,888; Índice de refracción $\left(20^{\circ} \mathrm{C}\right)$ 1,3670; gravedad especifica $\left(25^{\circ} \mathrm{C}\right)$ de 0,8991 y $0,041 \%$ de acidez.

- El aceite esencial de cedrón presenta pH de 2.10 y 2.15 de la muestra secada a medio ambiente y secada a $40^{\circ} \mathrm{C}$, respectivamente.
- El aceite esencial de cedrón obtenidas de la muestras secadas al medio ambiente presenta mejores características fisicoquímicas y químicas que lãs muestras secadas a $40^{\circ} \mathrm{C}$.

\section{REFERENCIAS BIBLIOGRÁFICAS}

- Bernardini, E. 1999. Tecnología de Aceites y Grasas. Editorial Alambra. Segunda Edición. Zaragoza - España. pág. 923.

- $\quad$ Cázares, L., Christen, M. y otros. 1989. Técnicas actuales de investigación documental. Editorial Trillas. Segunda Edición. México. pág. 63.

- Carhuancho F Greiz y Córdova Carrillo Wilfredo 2000. investigación fotoquímica y extracción de aceite esencial de la Eugenia Myrtomienta (Arrayán). Editorial Acribia. Primera Edición. Zaragoza- España. pág. 122-124

- Domínguez Xorge. A. 1999. Métodos de Investigación fotoquímica. Editorial Limusa. Segunda Edición. México. pág. 167

- Font Quer, P. 1995. Plantas Medicinales. Editorial Labor. Primera Edición. BarcelonaEspaña. pág. 180

- García Vallejo, M. C. 2000. Importancia de la Investigación química en la explotación de los aceites esenciales VII Jornadas sobre plantas aromáticas. Editorial Alcoy. Segunda Edición. México. pág. 93

- Gil Pavas E. Sáez Vega A. 2005. Evaluación a escala de planta piloto del proceso industrial para la obtención de aceite esencial de cardamomo, bajo la filosofía "cero emisiones". Editorial Medellín. Segunda Edición. Colombia. pág. 136

- Lok de Ugaz, Olga. 1999. Investigación Fotoquímica; Métodos en el estudio de Productos Naturales. Fondo Editorial. Primera Edición. Pontificia Universidad Católica del Perú. pág. 76.

- Martínez M, Alejandro. 2003. Aceites Esenciales. Editorial Medellín. Segunda Edición. Colombia. pág. 129.

- Martínez Moreno, J. M., Gómez Herrera, G., Janer del Valle, C. 2000. Estudios físicoquímicos sobre las pastas de aceitunas molidas: IV Las gotas de aceite, Grasas y Aceites. Editorial Acribia. Primera Edición. ZaragozaEspaña. pág. 112.

- Grosse y otros. 2000. Extracción del Aceite esencial de Naranja Cajera citrus. Editorial Caracas. Volumen 51. Venezuela. pág. 190-200.

- Smith, A Carlos. 1999. Control Automático De Procesos. Editorial Limusa S.A. Primera Edición. México. pág. 210. 
- Stashenko Elena E. 1998. Aceites esenciales: Técnicas de extracción y análisis Universidad Industrial de Santander. Editorial Acribia. Primera Edición. Zaragoza- España. pág. 156.

- Wanda Sellar. 2000. Guía de aceites Esenciales. Editorial Acribia. 6ta Edición. Madrid - España. pág. 145-149

- Zarate M, Ángel. 1989. Extracción y Aplicación del Aceite Esencial de Cedrón. Tesis UNCP, Facultad de Ingeniería en industrias alimentarias. Huancayo - Perú. pág. 87

- Zevallos. 1999. Enciclopedia de Ciencia y Tecnología. Editorial McGraw - Hill. Tomos I y IV. de México. Pág. 234-240 